Jurnal Health Sains: p-ISSN : 2723-4339 e-ISSN : 2548-1398

Vol. 2, No. 2, Februari 2021

\title{
HUBUNGAN RIWAYAT PENYAKIT INFEKSI DAN PENGASUHAN KELUARGA DENGAN KEJADIAN STUNTING ANAK TK DI KABUPATEN ACEH TENGAH
}

\author{
Rina Hudaya, Rahayu Lubis dan Etti Sudaryati
}

Universitas Sumatera Utara, Medan, Indonesia

Email: rinahudaya03@gmail.com, rahayu_lubis@yahoo.com dan etysudaryati@gmail.com

\begin{tabular}{|c|c|}
\hline ARTIKEL INFO & ABSTRACT \\
\hline $\begin{array}{l}\text { Tanggal diterima: } 5 \text { Februari } \\
2021 \\
\text { Tanggal revisi: } 15 \text { Februari } \\
2021 \\
\text { Tanggal yang diterima: } 25 \\
\text { Februari } 2021\end{array}$ & $\begin{array}{l}\text { Children who grow and develop healthy and educated, feel } \\
\text { safe and happy are the basis for increasing the good quality } \\
\text { of human resources. Nutritional deficiencies in a long time } \\
\text { and infection disease can cause the obtraction in their linear } \\
\text { growth which eventually causes stunting. The objective of the } \\
\text { research was to analyse the relation of infection disease that }\end{array}$ \\
\hline $\begin{array}{l}\text { Keywords: } \\
\text { Infection disease; Family care; } \\
\text { Stunting; Kindergarten } \\
\text { children }\end{array}$ & $\begin{array}{l}\text { is diarrheal disease and acute respiratory infections, family } \\
\text { care that is health care patterns and psychosocial care } \\
\text { patterns with stunting incidence towards kindergarten } \\
\text { children Central Aceh Regency. This study applied cross- } \\
\text { sectional design by involving } 200 \text { kindergarten children } \\
\text { aged 4-6 years. The data were gathered by using } \\
\text { questionnaires dealing with children's characteristics, } \\
\text { parental characteristics, history of infectious diseases and } \\
\text { family care. The child's height wasobtained by using } \\
\text { microtoise. The data were analyzed by chi-square test and } \\
\text { multiple logistic regression tests. There were } 32 \% \text { of } \\
\text { kindergarten children who experienced stunting. The results } \\
\text { indicated that there was a relation of diarrheal disease (p } \\
0,005 ; \text { OR }=3,48 ; 95 \% \text { CI }=1,49-8,10 .) \text {, health care } \\
\text { patterns }(p<0,001 ; \text { OR }=5,36 ; 95 \% \text { CI }=2,37-12,11) \text { and } \\
\text { psychosocial care patterns }(p<0,001 ; \text { OR }=9,07 ; 95 \% \text { CI } \\
4,54-18,13) \text { with the incidence of stunting towards } \\
\text { kindergarten children. There was no relation to acute } \\
\text { respiratory infections with the incidence of stunting towards } \\
\text { kindergarten children in Central Aceh Regency. }\end{array}$ \\
\hline
\end{tabular}

\begin{abstract}
ABSTRAK
Anak-anak yang tumbuh dan berkembang dengan sehat dan terdidik, merasa aman dan bahagia merupakan dasar menciptakan SDM yang berkualitas. Kekurangan gizi dalam waktu yang cukup lama dan adanya penyakit infeksi menyebabkan pertumbuhan linear terhambat sehingga memicu terjadinya stunting. Penelitian ini bertujuan menganalisis hubungan penyakit infeksi yaitu riwayat penyakit diare dan penyakit ISPA, pengasuhan keluarga yaitu pola asuh kesehatan dan pola asuh psikososial dengan kejadian stunting anak TK di Kabupaten Aceh Tengah.

Penelitian ini menggunakan desain Cross sectional dengan subjek sebanyak 200 anak TK berumur 4-6 tahun. Pengumpulan data menggunakan kuesioner meliputi data
\end{abstract}

Kata Kunci:

Penyakit Infeksi; Pengasuhan, Stunting; Anak TK 
karakteristik anak, karakteristik orang tua, riwayat penyakit infeksi dan pengasuhan keluarga. Tinggi badan anak diukur menggunakan microtoise. Analisis data menggunakan uji chi-square dan uji regresi logistic berganda. Terdapat $32 \%$ anak TK mengalami stunting. Hasil penelitian menunjukkan terdapat hubungan penyakit diare $(\mathrm{p}=0,005 ; \mathrm{OR}=3,48$; 95\% CI $=1,49-8,10$.), pola asuh kesehatan (p < 0,001; OR $=5,36 ; 95 \% \mathrm{CI}=2,37-12,11)$ dan pola asuh psikososial $(\mathrm{p}$ $<0,001 ; \mathrm{OR}=9,07 ; 95 \% \mathrm{CI}=4,54-18,13)$ dengan kejadian stunting pada anak TK. Riwayat penyakit ISPA tidak berhubungan dengan kejadian stunting pada anak TK di Kabupaten Aceh Tengah.

Coresponden Author:

Email: rinahudaya03@gmail.com Artikel dengan akses terbuka dibawah lisensi

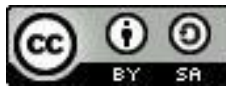

\section{Pendahuluan}

Anak-anak yang dapat tumbuh dan berkembang dengan sehat dan terdidik, bebas dari kemiskinan serta merasa aman dan bahagia merupakan dasar dalam menciptakan sumber daya manusia berkualitas sehingga berkontribusi bagi ekonomi dan masyarakat (Kementerian Perencanaan Pembangunan Nasional [Bappenas] \& United Nations Children's Fund (Staff, 2010). (Ulfah \& Muliawati, 2013) menyebutkan fase tumbuh kembang anak pada usia dini (0-6 tahun) merupakan fase golden age sekaligus fase kritis yang menentukan aspek fisik, psikis dan intelegensi anak serta berperan dalam tumbuh kembang di tahap selanjutnya. Gizi merupakan faktor utama dalam mendukung tumbuh kembang anak agar berjalan optimal (Fikawati \& Syafiq, 2017). Kekurangan gizi dalam waktu yang cukup lama dan adanya penyakit infeksi menyebabkan pertumbuhan linear terhambat sehingga memicu terjadinya stunting pada anak (Fikawati \& Syafiq, 2017).

Stunting dalam jangka pendek berdampak pada peningkatan angka morbiditas dan mortalitas anak, perkembangan motorik, kognitif dan bahasa anak yang menurun serta peningkatan pembiayaan kesehatan (Organization, 2013). Menurut (Astuti \& Purwaningsih, 2019) dampak jangka panjang dari stunting berupa perawakan tubuh yang pendek, menurunnya prestasi belajar, meningkatnya resiko obesitas dan penyakit kronis, menurunnya kapasitas dan produktivitas kerja. Selain itu, stunting pada wanita dapat menimbulkan gangguan pertumbuhan dan perkembangan janin, terhambatnya proses melahirkan serta meningkatkan risiko underweight dan stunting pada anak yang dilahirkan (Victora et al., 2008).

Berdasarkan data WHO 2019 secara global tahun 2018 terdapat 149 juta $(21,9 \%)$ anak di bawah lima tahun dalam kondisi stunting dan lebih dari $94 \%$ berasal dari negara-negara berkembang yaitu Asia (54.8\%) dan Afrika (39,4\%). Prevalensi stunting di Kawasan Asia tertinggi di Asia Selatan (32,7\%), disusul Asia Tenggara sebesar 25\%. Angka prevalensi stunting Indonesia berada pada posisi kelima di Asia Tenggara. Berdasarkan hasil riset kesehatan dasar tahun 2018, prevalensi stunting di Indonesia sebesar $30,8 \%$ dimana Provinsi Aceh menduduki posisi ketiga $(35,7 \%)$. Hal ini menunjukkan Aceh merupakan wilayah dengan prevalensi 
stunting yang tinggi yaitu 30-39\% (Organization, 2013).

Stunting disebabkan oleh beragam faktor yang saling terkait, diantaranya meliputi penyakit infeksi, pemberian asi, tindakan pemberian makanan yang tidak adekuat, serta aspek keluarga dan rumah tangga (Organization, 2013). Selain itu, Tim Nasional Percepatan Penanggulangan Kemiskinan (TNP2K) pada tahun 2017 menguraikan timbulnya stunting berkaitan dengan kurang baiknya praktik pengasuhan, layanan kesehatan yang masih terbatas bagi ibu hamil dan setelah melahirkan serta kualitas pendidikan usia dini yang masih terbatas, kurang teraksesnya makanan bergizi oleh keluarga, ditambah kurang teraksesnya air bersih dan sanitasi lingkungan oleh masyarakat.

Hasil penelitian (Arifin et al., 2013) dan penelitian (Picauly \& Toy, 2013) menunjukkan bahwa penyakit infeksi berhubungan dengan kejadian stunting. Disamping itu, pengasuhan keluarga juga memiliki hubungan dengan kejadian stunting pada balita (Sari, 2020). Menurut (Wiyono et al., 2019) pengasuhan dimanifestasikan dalam pola asuh makan, pola asuh kesehatan, pola asuh psikososial serta pola asuh kebersihan diri dan sanitasi lingkungan. Berdasarkan hasil penelitian Aryastami dan Tarigan tahun 2017, kejadian stunting banyak dialami oleh anak umur 4-6 tahun meskipun pada umur 0-2 tahun anak tersebut tumbuh normal. Penelitian ini ingin menganalisis hubungan riwayat penyakit infeksi yaitu penyakit diare dan ispa serta pengasuhan keluarga yang terdiri dari pola asuh kesehatan dan pola asuh psikososial dengan kejadian stunting anak TK di Kabupaten Aceh Tengah.

\section{Metode Penelitian}

Jenis penelitian yang digunakan adalah observasional analitik dengan desain cross sectional. Penelitian ini dilaksanakan di
Kabupaten Aceh Tengah pada bulan Maret sampai bulan Apri 2020. Lokasi ini dipilih karena Kabupaten Aceh Tengah merupakan salah satu dari 100 Kabupaten/Kota prioritas untuk intervensi stunting dari Provinsi Aceh (TNP2K, 2017). Populasi target yaitu anak sekolah Taman kanak-kanak di Wilayah Kabupaten Aceh Tengah dimana populasi terjangkau diambil dari seluruh anak sekolah TK di Wilayah Kecamatan Bies, Kecamatan Bintang, Kecamatan Pegasing dan Kecamatan Kute Panang.

Teknik pengambilan sampel menggunakan teknik multistage random sampling dengan area populasi Kabupaten Aceh Tengah. Tahapan selanjutnya yaitu berturut-turut didapatkan 4 kecamatan terpilih yaitu Kecamatan Bintang terdiri dari 4 desa (4 sekolah TK), kecamatan Bies terdiri dari 2 desa (2 TK), Kecamatan Pegasing terdiri dari 5 desa (5 TK) dan Kecamatan Kute panang terdiri dari 3 desa (3 TK). Seluruh anak TK yang berumur 4-6 tahun dari 14 TK diambil sebagai subjek yang ditetapkan hingga mencapai jumlah 200 subjek. Untuk memilih pasangan ibu-anak dilakukan secara random berdasarkan daftar peserta didik dari setiap sekolah TK. Anak-anak TK yang berusia kurang dari 4 tahun dan lebih dari 6 tahun, memiliki cacat bawaan (bongkok dan pincang) serta ibu yang menolak berpartisipasi dalam penelitian dikeluarkan dari kerangka sampel.

Pengumpulan data primer melalui metode wawancara secara terstruktur menggunakan kuesioner, meliputi data karakteristik anak, karakteristik orang tua, riwayat penyakit infeksi (diare dan ispa) serta pengasuhan keluarga yang terdiri dari pola asuh kesehatan dan pola asuh psikososial. Selain itu, stunting (variabel dependen) diperoleh melalui pengukuran tinggi badan anak menggunakan microtoise ketelitian 0,1 $\mathrm{cm}$. Hasil pengukuran disesuaikan dengan umur dan jenis kelamin anak (TB/U) berdasarkan standar WHO Multicentre 
Growth Reference Study (MGRS) 2006 untuk anak umur 4-5 tahun dan WHO Reference 2007 untuk anak umur 5-6 tahun. Hasil pengukuran $\mathrm{TB} / \mathrm{U}$ tersebut dibagi menjadi dua kategori yaitu stunting (Z-score TB/U $<-2 \mathrm{SD})$ dan normal (Z-score $\mathrm{TB} / \mathrm{U} \geq-2 \mathrm{SD})$.

Analisis data dilakukan secara univariat, bivariat dengan uji chi-square dan multivariat dengan uji regresi logistic berganda. Tahapan analisis multivariat dalam penelitian ini yaitu: a) jika hasil uji bivariat antara variabel independen dengan variabel dependen menghasilkan $\mathrm{p}<0,25$ maka variabel tersebut dimasukkan dalam uji regresi logitik ganda; b) melakukan analisis multivariat dimana semua variabel independen yang masuk dalam proses ini dianalisis secara bersama-sama dengan metode enter. Penelitian ini telah mendapatkan Persetujuan Komisi Etik Penelitian Kesehatan Fakultas Keperawatan USU Nomor 2136/III/SP/2020.

\section{Hasil dan Pembahasan}

Jenis kelamin anak TK dalam penelitian ini diperoleh secara berimbang yaitu 50\% berjenis kelamin laki-laki dan $50 \%$ berjenis kelamin perempuan. Mayoritas anak berumur 5 tahun 1 bulan sampai 6 tahun 169 orang $(84,50 \%)$. Karakteristik orang tua dalam penelitian ini mayoritas ayah berumur antara 36-45 tahun sebanyak 100 orang (50\%) dan ibu berumur antara 26-35 tahun yaitu 106 orang $(53 \%)$. Hasil penelitian menunjukkan orang tua umumnya berpendidikan tinggi $(\geq$ SMA) yaitu ayah sebesar 52,5\% dan ibu sebesar 60\%. Kabupaten Aceh Tengah dikenal sebagai wilayah pertanian sehingga dalam penelitian ini juga diperoleh pekerjaan ayah terutama sebagai petani yaitu sebanyak 139 orang $(69,5 \%)$ dan sebanyak 108 orang ibu merupakan IRT.

\section{Tabel 1}

\section{Distribusi frekuensi berdasarkan Penyakit} Infeksi, Pengasuhan Keluarga dan Kejadian Stunting

\begin{tabular}{lcc}
\hline Variabel & $\mathbf{N = 2 0 0}$ & $\%$ \\
\hline Riwayat Penyakit Diare Anak & & \\
\hline Ya & $\mathbf{2 6}$ & $\mathbf{1 3 , 0 0}$ \\
\hline Tidak & $\mathbf{1 7 4}$ & \\
\hline Riwayat Penyakit Ispa Anak & & \\
\hline Ya & $\mathbf{9 5}$ & $\mathbf{4 7 , 5 0}$ \\
\hline Tidak & $\mathbf{1 0 5}$ & $\mathbf{5 2 , 5 0}$ \\
\hline Pola Asuh Kesehatan & & \\
\hline Kurang baik & $\mathbf{1 3 3}$ & $\mathbf{6 6 , 5 0}$ \\
\hline Baik & $\mathbf{6 7}$ & $\mathbf{3 3 , 5 0}$ \\
\hline Pola Asuh Psikosial & & \\
\hline Kurang baik & $\mathbf{8 5}$ & $\mathbf{4 2 , 5 0}$ \\
\hline Baik & 115 & $\mathbf{5 7 , 5 0}$ \\
\hline Kejadian Stunting & & \\
\hline Ya & $\mathbf{6 4}$ & $\mathbf{3 2 , 0 0}$ \\
\hline Tidak & $\mathbf{1 3 6}$ & $\mathbf{6 8 , 0 0}$ \\
\hline
\end{tabular}

Riwayat penyakit infeksi yang umum dialami anak usia dini adalah penyakit diare dan ISPA. Hasil penelitian pada Tabel 1. menunjukkan sebanyak 26 anak mengalami diare $\geq 2$ kali dalam 3 bulan terakhir dan terdapat 95 anak mengalami ISPA dalam 3 bulan terakhir sebanyak $\geq 3$ kali. Pengasuhan keluarga menggambarkan peran keluarga terutama ibu dalam pemenuhan kebutuhan anak yang terdiri dari pola asuh kesehatan dan pola asuh psikososial. Hasil penelitian menggambarkan mayoritas responden memiliki pola asuh kesehatan yang kurang baik yaitu sebesar $66,5 \%$. Sedangkan untuk pola asuh psikososial telah menerapkan pola asuh yang baik sebesar $57,7 \%$. Kejadian stunting anak TK dalam penelitian ini sebanyak 64 orang $(32,0 \%)$ dimana 51,6 persen (33 orang) berjenis kelamin laki-laki.

Hasil penelitian menunjukkan bahwa terdapat hubungan penyakit diare yang dialami anak dengan kejadian stunting $(\mathrm{p}=0,005$; OR $=3,48 ; 95 \% \mathrm{CI}=1,49<\mathrm{OR}<8,10$.). Hasil uji statistik menunjukkan tidak terdapat hubungan penyakit ISPA anak dengan kejadian stunting $(\mathrm{p}=0,347 ; \mathrm{OR}=1,39 ; 95 \% \mathrm{CI}=0,77<\mathrm{OR}<$ 2,53). Hasil uji statistik aspek pengasuhan keluarga menunjukkan adanya hubungan pola 
asuh kesehatan $(\mathrm{p}<0,001 ; \mathrm{OR}=5,36 ; 95 \% \mathrm{CI}$ $=2,37<\mathrm{OR}<12,11)$ dan pola asuh psikososial $(\mathrm{p}<0,001 ; \mathrm{OR}=9,07 ; 95 \% \mathrm{CI}=$ $4,54<\mathrm{OR}<18,13)$ dengan kejadian stunting pada anak TK (Tabel 2).

\section{Tabel 2}

Hubungan Riwayat Penyakit Infeksi dan Pengasuhan Keluarga dengan Stunting Anak TK

\begin{tabular}{|c|c|c|c|c|c|c|c|c|}
\hline \multicolumn{9}{|c|}{ Kejadian Strunting } \\
\hline \multirow[t]{2}{*}{ Variabel } & \multicolumn{2}{|c|}{$\mathbf{Y a}$} & \multicolumn{2}{|c|}{ Tidak } & \multicolumn{2}{|c|}{ Total } & \multirow[t]{2}{*}{$\mathbf{P}$} & \multirow{2}{*}{$\begin{array}{c}\begin{array}{c}\text { Nilai OR } \\
(95 \%)\end{array} \\
\end{array}$} \\
\hline & $\mathbf{N}$ & $\%$ & $\mathbf{N}$ & $\%$ & $\mathbf{N}$ & $\%$ & & \\
\hline \multicolumn{9}{|l|}{$\begin{array}{c}\text { Penyakit } \\
\text { Diare }\end{array}$} \\
\hline Ya & 15 & 57,7 & 11 & 42,3 & 26 & 100,0 & 0,005 & $\begin{array}{c}3,43 \\
(1,498,10) \\
\end{array}$ \\
\hline Tidak & 49 & 28,2 & 125 & 71,8 & 174 & 100,0 & & \\
\hline \multicolumn{9}{|l|}{$\begin{array}{c}\text { Penyakit } \\
\text { Ispa }\end{array}$} \\
\hline Ya & 34 & 35,8 & 61 & 64,2 & 95 & 100,0 & $\mathbf{0 , 3 4 7}$ & $\begin{array}{c}1,39 \\
(0,77253) \\
\end{array}$ \\
\hline Tidak & 30 & 28,6 & 75 & 71,4 & 105 & 100,0 & & \\
\hline \multicolumn{9}{|l|}{$\begin{array}{l}\text { Pola Asuh } \\
\text { Kesehatan }\end{array}$} \\
\hline $\begin{array}{c}\text { Kurang } \\
\text { Baik }\end{array}$ & 56 & 42,1 & 77 & 57,9 & 133 & 100,0 & & $\begin{array}{c}5,36 \\
(23712,11) \\
\end{array}$ \\
\hline Baik & 8 & 11,9 & 59 & 88,1 & 67 & 100,0 & 0,001 & \\
\hline \multicolumn{9}{|c|}{$\begin{array}{l}\text { Pola Asuh } \\
\text { Psikososial }\end{array}$} \\
\hline $\begin{array}{c}\text { Kurang } \\
\text { baik }\end{array}$ & 49 & 57,6 & 36 & 42,4 & 85 & 100,0 & & $\begin{array}{c}9,07 \\
(4,541813) \\
\end{array}$ \\
\hline Baik & 15 & 13,0 & 100 & 87,0 & 115 & 100,0 & 0,001 & \\
\hline
\end{tabular}

Berdasarkan hasil uji chi-square, variable yang dapat dimasukkan dalam uji regresi logistic berganda $(\mathrm{p}<0,25)$ yaitu penyakit diare, pola asuh kesehatan dan pola asuh psikososial. Sedangkan riwayat penyakit ISPA dikeluarkan dari model regresi logistik. Hasil uji regresi logistik menunjukkan terdapat hubungan signifikan penyakit diare, pola asuh kesehatan dan pola asuh psikososial dengan stunting $(\mathrm{p}<0,05)$ dengan masing-masing nilai OR adalah sebesar 7,34; 5,93 dan 10,18 (Tabel $3)$.

Tabel 3

Hasil Uji Regresi Berganda Hubungan Riwayat Penyakit Infeksi dan Pengasuhan Keluarga dengan Stunting Anak TK

\begin{tabular}{lccccc}
\hline \multicolumn{1}{c}{ Variabel } & B & SE & P & OR & 95\%Cl \\
\hline $\begin{array}{l}\text { Penyakit } \\
\text { Diare }\end{array}$ & 1,994 & $\mathbf{0 , 5 5 1}$ & $<0,001$ & 7,341 & $\mathbf{2 , 4 9 3 -}$ \\
\hline $\begin{array}{l}\text { Pola Asuh } \\
\text { Kesehatan }\end{array}$ & 1,786 & 0,494 & $<0,001$ & $\mathbf{5 , 9 3 6}$ & $\mathbf{2 , 2 6 4 -}$ \\
\hline
\end{tabular}

\begin{tabular}{lccccc}
\hline $\begin{array}{l}\text { Pola Asuh } \\
\text { Psikososial }\end{array}$ & 2,321 & $\mathbf{0 , 3 9 9}$ & $<0,001$ & $\mathbf{1 0 , 1 8 6}$ & $\begin{array}{l}4,659- \\
22,269\end{array}$ \\
\hline Konstanta & $\mathbf{3 , 6 1 3}$ & $\mathbf{0 , 5 5 7}$ & $<0,001$ & & \\
\hline
\end{tabular}

Stunting merupakan kondisi

terhambatnya pertumbuhan linear yang sangat umum ditemukan di negara-negara berkembang (Danaei et al., 2016). Penelitian ini menunjukkan sebanyak $32,0 \%$ anak TK usia 4-6 tahun mengalami stunting, sedangkan data PSG Provinsi Aceh prevalensi stunting pada balita di Kabupaten Aceh tengah tahun 2017 sebesar 37,2\% (Aceh, 2018). Keadaan ini menggambarkan stunting masih menjadi masalah kesehatan masyarakat khususnya anak umur 4-6 tahun di wilayah Kabupaten Aceh Tengah yang berada dalam kategori prevalensi tinggi yaitu 30-39\% (Organization, 2013)

Pertumbuhan linear terhambat disebabkan oleh kondisi kesehatan yang kurang optimal, nutrisi dan perawatan/pengasuhan yang tidak memadai (De Onis \& Branca, 2016). Kondisi kesehatan yang kurang optimal ditandai dengan adanya riwayat penyakit infeksi yang dialami anak. Hasil penelitian menunjukkan terdapat hubungan penyakit diare dengan kejadian stunting. Penelitian di Puskesmas Simolawang Surabaya menunjukkan riwayat penyakit diare dalam 3 bulan terakhir dapat meningkatkan risiko stunting pada balita sebesar 3, 6 kali dengan $p=0,025$ (Desyanti \& Nindya, 2017). Hasil ini sejalan dengan dilakukan oleh (Nasikhah \& Margawati, 2012) di Semarang Timur serta penelitian (Semba, 2017) pada anak prasekolah di Indonesia Indonesia. Selama diare terjadi malabsorsi zat gizi, dehidrasi dan kehilangan zat gizi. Bila kondisi ini tidak segera ditangani dan diimbangi dengan asupan makanan yang adekuat maka timbul dehidrasi berat, malnutrisi serta gagal tumbuh (Dewey \& Mayers, 2011).

Jenis penyakit infeksi terbanyak yang dialami responden adalah infeksi saluran pernapasan atas, yaitu sebesar $47,5 \%$. Penyakit ini masih merupakan salah satu masalah 
kesehatan masyarakat yang utama karena angka kejadiannya masih tinggi terutama pada balita. Hasil penelitian ini menunjukkan penyakit ispa tidak berhubungan dengan kejadian stunting $(\mathrm{p}=0,347)$. Hal ini sesuai dengan hasil penelitian (Halim et al., 2018) mengenai stunting pada anak usia 3-5 tahun di PAUD/TK di kecamatan tuminting Kota Manado ( $\mathrm{p}=0,162)$. Infeksi ini tergolong ringan, dimana demam disertai batuk pilek berlangsung 2-3 hari (Roche \& Sun, 2005). Infeksi ini dapat sembuh dengan sendirinya dalam waktu singkat dan tidak mempengaruhi nafsu makan anak sehingga tidak menurunkan status gizi anak dan memicu stunting.

Pola asuh kesehatan merupakan hal-hal yang dilakukan untuk mempertahankan status gizi anak, menjauhkan dan menghindarkan penyakit serta yang dapat menyebabkan menurunnya keadaan kesehatan anak (Apriyanto, 2016). Hasil penelitian ini menunjukkan pola asuh kesehatan memiliki hubungan dengan kejadian stunting ( $\mathrm{p}<0,001$; OR: 5,3). Penelitian ini sejalan dengan penelitian di Kabupaten Sijunjung (Power et al., 2015) dan Kota Subulussalam (Lestari et al., 2014). Keaktifan orang tua dalam memantau pertumbuhan dan perkembangan anak sangat diperlukan. Menurut (Mita \& Husni, 2017) saat orang tua bersedia membawa anak ke posyandu, anak akan memperoleh kapsul vitamin A dan obat cacing sebanyak dua kali dalam setahun serta anak mendapat pengukuran status gizi melalui penimbangan berat badan dan pengukuran tinggi badan. Upaya-upaya ini dapat membantu orang tua memastikan optimalnya kondisi kesehatan dan tumbuh kembang anak.

Menurut (Brooks \& McLennan, 2012), pola asuh psikososial merupakan praktek yang diberikan oleh pengasuh terutama ibu yang diperlukan anak dalam proses tumbuh kembangnya berupa pemberian rangsangan/ stimulus dan dukungan emosional. Berdasarkan hasil uji statistik ditemukan bahwa terdapat hubungan yang bermakna antara pola asuh psikososial dengan kejadian stunting ( $\mathrm{p}<0,001 ;$ OR $=9,074)$. Hasil penelitian Rahmayana tahun 2014 dan Noftalina tahun 2019 juga menunjukkan pola asuh psikososial secara signifikan berhubungan dengan stunting. Teori positive deviance menguraikan bahwa rangsangan atau stimulus yang diterima anak dari ibu / pengasuh secara rutin berupa visual, kata-kata (verbal) dan auditif dapat menstimulasi produksi hormon pertumbuhan (growth hormone), mendorong normalnya metabolisme energi dan kondisi respon imun yang lebih baik. Buruknya kondisi psikososial anak diprediksi mempengaruhi penggunaan zat gizi secara negatif dalam tubuh anak. Disamping itu, asuhan psikososial yang baik terkait juga dengan baiknya asuhan gizi dan kesehatan sehingga berdampak positif secara tidak langsung pada kondisi gizi, pertumbuhan serta perkembangan anak (Diasmarani, 2011).

\section{Kesimpulan}

Terdapat hubungan yang signifikan antara riwayat penyakit infeksi yaitu penyakit diare pada anak, pola asuh kesehatan dan pola asuh psikosial keluarga dengan kejadian stunting anak TK di Kabupaten Aceh Tengah. Program mengatasi stunting perlu dimulai dari peningkatan kualitas pengasuhan orang tua. Para orang tua diharapkan lebih memperhatikan dan menerapkan asuhan yang baik demi pertumbuhan dan perkembangan anak yang optimal dngan mengikuti kegiatankegiatan edukasi melalui kelas ibu hamil atau pos gizi yang diselenggarakan pihak puskesmas dan kegiatan parenting lainnya dari sekolah.

\section{BIBLIOGRAFI}

Aceh, D. (2018). Profil Kesehatan Aceh Tahun 2017. In Banda Aceh.

Apriyanto, M. (2016). Study On Effect Of Fermentation To The Quality Parameter 
Of Cocoa Bean In Indonesia. Asian $J$. Dairy \& Food Res, 35(2), 160-163.

Arifin, S. U., Mayulu, N., \& Rottie, J. (2013). Hubungan Asupan Zat Gizi Dengan Kejadian Anemia Pada Anak Sekolah Dasar Di Kabupaten Bolaang Mongondow Utara. Jurnal Keperawatan, 1(1).

Astuti, F. P., \& Purwaningsih, H. (2019). Peningkatan Pengetahuan Masyarakat Tentang Stunting Dan Gizi Balita Di Desa Rogomulyo Kecamatan Kaliwungu. Indonesian Journal of Community Empowerment (Ijce), 1(2).

Brooks, D. R., \& Mclennan, D. A. (2012). The Nature Of Diversity: An Evolutionary Voyage Of Discovery. University of Chicago Press.

Danaei, G., Andrews, K. G., Sudfeld, C. R., Fink, G., Mccoy, D. C., Peet, E., Sania, A., Smith Fawzi, M. C., Ezzati, M., \& Fawzi, W. W. (2016). Risk Factors For Childhood Stunting In 137 Developing Countries: A Comparative Risk Assessment Analysis At Global, Regional, And Country Levels. Plos Medicine, 13(11), E1002164.

De Onis, M., \& Branca, F. (2016). Childhood Stunting: A Global Perspective. Maternal \& Child Nutrition, 12, 12-26.

Desyanti, C., \& Nindya, T. S. (2017). Hubungan Riwayat Penyakit Diare Dan Praktik Higiene Dengan Kejadian Stunting Pada Balita Usia 24-59 Bulan Di Wilayah Kerja Puskesmas Simolawang, Surabaya. Amerta Nutrition, 1(3), 243-251.

Dewey, K. G., \& Mayers, D. R. (2011). Early Child Growth: How Do Nutrition And Infection Interact? Maternal \& Child Nutrition, 7, 129-142.

Diasmarani, N. (2011). Karakteristik Dan Perkembangan Bahasa Anak Balita Stunted Di Desa Sukawening Kabupaten
Bogor. Jurusan Gizi Masyarakat. Fakultas Ekologi Manusia. Ipb, Bogor.

Fikawati, S., \& Syafiq, A. (2017). Maternal Calorie Intake Is A Significant Factor Associated With 6 Months Of Exclusive Breastfeeding Among Lactating Mothers In Depok City, Indonesia. Malaysian Journal Of Nutrition, 23(1).

Halim, R., Hana, M., \& Mardhiyah, M. (2018). Gambaran Asupan Cairan Dan Status Gizi Pada Mahasiswa Kedokteran Universitas Jambi. Jambi Medical Journal" Jurnal Kedokteran Dan Kesehatan", 6(1), 68-75.

Lestari, D. P., Syafrizal, S., \& Elfrida, E. (2014). An Analysis Of Politeness Language Patterns In Request Used In English Textbook Of Second Grade Of Junior High School. A Thesis Presented In Partial Fulfillment Of Sarjana Degree Of English Language Education, Indonesia, University Of Bengkulu.

Mita, S. R., \& Husni, P. (2017). Pemberian Pemahaman Mengenai Penggunaan Obat Analgesik Secara Rasional Pada Masyarakat Di Arjasari Kabupaten Bandung. Dharmakarya, 6(3).

Nasikhah, R., \& Margawati, A. (2012). Faktor Risiko Kejadian Stunting Pada Balita Usia 24-36 Bulan Di Kecamatan Semarang Timur. Diponegoro University.

Organization, W. H. (2013). Global Tuberculosis Report 2013. World Health Organization.

Picauly, I., \& Toy, S. M. (2013). Analisis Determinan Dan Pengaruh Stunting Terhadap Prestasi Belajar Anak Sekolah Di Kupang Dan Sumba Timur, Ntt. Jurnal Gizi Dan Pangan, 8(1), 55-62.

Power, D., Santoso, N., Dieringer, M., Yu, J., Huang, H., Simpson, S., Seth, I., Miao, H., \& Zhu, J. (2015). Ifi44 Suppresses Hiv-1 Ltr Promoter Activity And 
Hubungan Riwayat Penyakit Infeksi Dan Pengasuhan Keluarga Dengan Kejadian Stunting Anak Tk Di Kabupaten Aceh Tengah

Facilitates Its Latency. Virology, 481, $142-150$.

Roche, A. F., \& Sun, S. S. (2005). Human Growth: Assessment And Interpretation. Cambridge University Press.

Sari, M. (2020). Analisis Pengukuran Kinerja Sumber Daya Manusia Menggunakan Metode Human Resource Scorecard (Studi Pada Pt Bprs Way Kanan). Uin Raden Intan Lampung.

Semba, N. A. La. (2017). Hubungan Antara Komitmen Organisasi Dengan Organizational Citizenship Behavior Pada Pegawai Negeri Sipildi Lembaga Penjaminan Mutu Pendidikan (Lpmp) Provinsi Sumatera Selatan. Universitas Mercu Buana Yogyakarta.

Staff, U. (2010). Unicef Annual Report 2009. Unicef.

Tnp2k, P. U. (2017). Program Keluarga Harapan Meraih Keluarga Sejahtera. Jakarta: Kementrian Sosial Ri.

Ulfah, M., \& Muliawati, N. N. (2013). Konsep Dasar Paud/Suyadi. Remaja Rosdakarya.

Victora, C. G., Adair, L., Fall, C., Hallal, P. C., Martorell, R., Richter, L., Sachdev, H. S., \& Group, M. And C. U. S. (2008). Maternal And Child Undernutrition: Consequences For Adult Health And Human Capital. The Lancet, 371(9609), 340-357.

Wiyono, B. B., Kusumaningrum, D. E., Gunawan, I., \& Ardiansyah, M. (2019). Implementation Of School Management Based On A Balanced Scorecard And Its
Relationship With Headmaster Attributes In Indonesia. Int. J. Innov. Creat. Chang, 5(4), 164-179. 